\title{
Roscovitine inhibits endotoxin-induced lung inflammation in mice lacking peptidylprolyl cis/trans isomerase, NIMA- interacting 1 (PIN1)
}

\author{
Benjamin W Newell, Amelia M Spaulding, Nam Y Lee and Dale G Hoyt* \\ Division of Pharmacology, The Ohio State University College of Pharmacy and The Dorothy M. Davis Heart and Lung Research Institute, Columbus, OH 43210, \\ USA
}

\begin{abstract}
Deletion of peptidylprolyl cis/trans isomerase, NIMA-interacting 1 (PIN1), a rotamase that modulates effects of proline-directed serine/threonine phosphorylation, increased lung inflammation caused by E. coli endotoxin (lipopolysaccharide, LPS) in mice. Here, the effect of roscovitine, an inhibitor of several proline-directed cyclin-dependent kinases, on LPS-induced inflammation was determined. LPS (1.5 mg/kg, ip) increased pulmonary neutrophils in PIN1 knockout more than in wildtype mice. Cyclooxygenase- 2 expression was elevated in wildtype and knockout mouse lung, and to a greater extent in $\mathrm{knockouts}$. Roscovitine (70 mg/kg, ip, 30 min before LPS) inhibited the accumulation of neutrophils and induction of cyclooxygenase-2 in PIN1 knockout mouse lung. The drug did not reduce the more moderate level of inflammation caused by this dose of LPS in wildtype mouse lungs, or the greater inflammation caused by a higher dose of LPS (6 mg/kg) in wildtype mice. The results indicate roscovitine inhibits LPS-induced lung inflammation in mice lacking PIN1. CDK antagonists might be able to limit endotoxin-associated inflammatory responses where PIN1 function is reduced.
\end{abstract}

\begin{abstract}
Abbreviations: CDK: Cyclin dependent kinase; COX2: Cyclooxygenase-2; DMSO: Dimethylsulfoxide; LPS: Lipopolysaccharide; iNOS: Inducible nitric oxide synthase; MPO: Myeloperoxidase; PIN1: Peptidylprolyl cis/trans isomerase NIMAinteracting 1; PBS: Phosphate-buffered saline; S: Serine; T: Threonine; P: Proline
\end{abstract}

\section{Introduction}

Lungs are sensitive to inflammatory actions of lipopolysaccharide (LPS) of Gram-negative bacteria. LPS increases vascular permeability leading to edema, induces endothelial adhesion molecules, and causes neutrophils to accumulate in lung. These events eventually compromise respiratory function [1].

Previously, it was found that knockout of peptidylprolyl cis/trans isomerase, NIMA-interacting 1 (PIN1) increased the sensitivity of mouse lung to LPS [2]. PIN1 acts specifically on phosphorylated (p) serine $(\mathrm{S})$ or threonine $(\mathrm{T})$-proline $(\mathrm{P})$ motifs in proteins $[3,4]$. Catalysis of the otherwise sterically-hindered rotation of the $\mathrm{p}(\mathrm{S} / \mathrm{T})-\mathrm{P}$ bond by PIN1 allows phosphorylated proteins to adopt different conformations. PIN1 is the only mammalian enzyme known to have this function. As a result, PIN1 can affect all aspects of protein function [3-11].

LPS activates several protein kinases that target S/T-P motifs in proteins [12-14]. One group of proline-directed kinases is the cyclindependent kinase (CDK) family [15]. At least one CDK, CDK5, is activated by LPS in murine hippocampus [13]. Modulation of CDK activity would presumably affect the pool of PIN1 substrates, some of which may contribute to inflammatory actions of LPS. The CDKinhibitor, roscovitine, antagonized CDK5-dependent phosphorylation of hippocampal Tau protein in LPS-treated mice suggesting that CDK inhibitors have anti-inflammatory activity [15]. In support of this, roscovitine also antagonized induction of cyclooxygenase-2 (COX2) and inducible nitric oxide synthase (iNOS) by LPS in RAW264 macrophages [16,17].

Roscovitine inhibited pulmonary effects of responses to Gram-positive agents and ventilator-induced lung injury $[18,19]$. Whether roscovitine affects Gram-negative E. coli LPS-induced lung inflammation is unknown. Given the influence of PIN1 knockout in LPS-treated mice, the effect of roscovitine in wildtype (+/+) and PIN1knockout (-/-) mice was investigated here.

\section{Materials and methods}

\section{Reagents}

Phosphate-buffered saline (PBS) and tris-glycine gels were from Invitrogen Corporation (Grand Island, NY). Bradford reagent, B-mercaptoethanol, dithiothreitol, dimethylsulfoxide (DMSO), deoxycholic acid, phenylarsine oxide, phenylmethylsulfonyl fluoride, $\mathrm{NaF}$, and E. coli LPS, serotype 0111:B4, were obtained from Sigma Chemical Co. (St Louis, MO). R-Roscovitine was purchased LC Laboratories (Woburn, MA). Bromphenol blue, ethylenediamine tetraacetic acid, sodium dodecyl sulfate, $\mathrm{NaCl}, \mathrm{Na}_{3} \mathrm{VO}_{4}, \mathrm{NaF}$, Tween 20, and Tris-base were obtained from Fisher Scientific (Fair Lawn, NJ). Aprotinin, leupeptin and carbobenzoxy-valyl-phenylalaninal were

Correspondence to: Dale G. Hoyt, Division of Pharmacology, The Ohio State University College of Pharmacy, 500 West Twelfth Avenue, Columbus, $\mathrm{OH}$, 43210 USA; Tel: 614-292-6245; Fax: 614-292-9083; E-mail: hoyt.27@osu.edu

Key words: cyclin-dependent kinase, endotoxin, lung, roscovitine

Received: June 11, 2016; Accepted: July 14, 2016; Published: July 18, 2016 
purchased from Calbiochem (La Jolla, CA).

Antibodies used were against COX2, from Cayman Chemical Co. (Ann Arbor, MI), myeloperoxidase (MPO), from Santa Cruz Biotechnology (Santa Cruz, CA), a-tubulin from Cell Signaling Technology (Danvers, MA), and PIN1, from R\&D Systems (Minneapolis, $\mathrm{MN}$ ). Enhanced chemiluminescence reagents and triton X-100 were from Pierce (Rockford, IL). Goat anti-mouse and -rabbit antibodies conjugated with horseradish peroxidase were purchased from Jackson Immunoresearch Laboratories, Inc. (West Grove, PA) and Santa Cruz Biotechnology (Santa Cruz, CA).

\section{Mice and treatments}

C57Bl/6 +/+ and PIN1 -/- mice [20] were used in congruence with the Guide for the Care and Use of Laboratory Animals from the U.S. National Institutes of Health under a protocol approved by the Ohio State University Institutional Animal Care and Use Committee. Mice were injected ip with DMSO or roscovitine in DMSO $(70 \mathrm{mg} / \mathrm{kg})$. After $30 \mathrm{~min}, \mathrm{PBS}$ or 1.5 or $6 \mathrm{mg} \mathrm{LPS} / \mathrm{kg}$ was administered ip. Tissue was harvested after $6 \mathrm{~h}$. Mice were euthanized, lungs were collected and stored frozen until use.

\section{Western blotting}

Tissue was homogenized in lysis buffer (50 mM Tris, $\mathrm{pH}$ 7.5, 250 $\mathrm{mM} \mathrm{NaCl}, 1 \%$ Triton-X-100, $20 \mathrm{mM} \mathrm{NaF}, 5 \mathrm{mM}$ EDTA, $4 \mathrm{mM} \mathrm{NaVO}_{4}$, $1 \mathrm{mM}$ phenylarsine oxide, $30 \mu \mathrm{g}$ aprotinin and leupeptin/ml, $25 \mu \mathrm{M}$ carbobenzoxy-valyl-phenylalaninal, $1 \mathrm{mM}$ phenylmethylsulfonyl fluoride, $0.01 \%$ deoxycholic acid) and sonicated. Protein was measured [21] and samples were denatured as described previously [2]. Samples were separated by SDS-polyacrylamide gel electrophoresis, transferred to nitrocellulose, and incubated with primary antibodies and horseradish peroxidase-conjugated secondary antibodies. Enhanced chemiluminescence was used to expose film. Images were produced by transilluminating scanning. Signal intensity was determined with NIH Image J software, and divided by value for $\alpha$-tubulin in each sample, as described before [2].

\section{Data analysis}

Student's t-test or analysis of variance with correction for multiple comparisons was used to analyze results [22].

\section{Results}

LPS at $1.5 \mathrm{mg} / \mathrm{kg}$ increased lung neutrophils, indicated by MPO, in PIN1 -/- mice and +/+ mice (Figures 1 and 2). The increase was 15fold in $-/$ - and 5 -fold $+/+$ lungs. Roscovitine reduced the accumulation of MPO by $42 \%$ (to 8.9 -fold above saline) in LPS-treated -/- mice. However, roscovitine did not significantly reduce the lower level of MPO in LPS-treated $+/+$ mice. In addition, roscovitine did not inhibit the response in $+/+$ mice treated with a higher dose of $6 \mathrm{mg} / \mathrm{kg}$ LPS, where MPO increased to $1960+470 \%$ (mean + SE) of saline, and 2589 $+806 \%$ of saline with roscovitine pre-treatment (not different).

LPS increased lung COX2 expression in $+/+$ and -/- mouse lung (Figure 3). The increase was 1.8 times greater in $-/-$ mice. Roscovitine also reduced the high level of COX2 in -/- lungs, but did not reduce the lesser COX2 expression in $+/+$ mouse lung.

\section{Discussion}

Previously, we found that PIN1 knockout increased the sensitivity of mice to LPS-induced lung inflammation (Liu et al., 2014). This

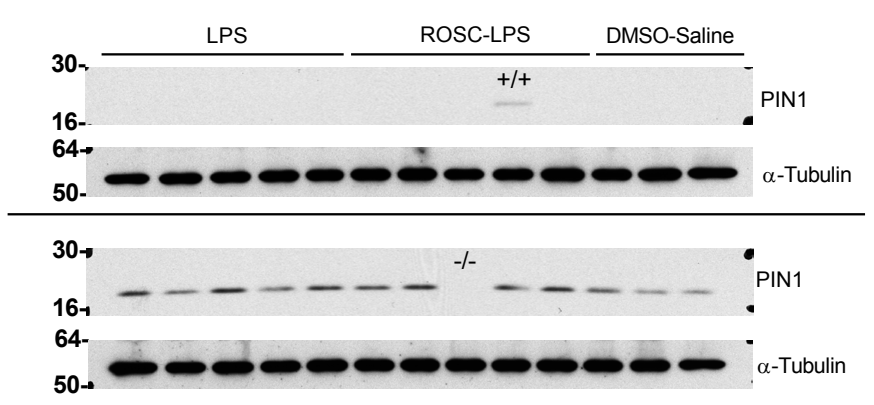

Figure 1. Western blots of PIN1 in wildtype (+/+) and PIN1 knockout (-/-) mice. Mice were treated DMSO or roscovitine ( $70 \mathrm{mg} / \mathrm{kg}$, ROSC) and then with saline or $1.5 \mathrm{mg}$ LPS $\mathrm{kg}$. Proteins were extracted $6 \mathrm{~h}$ later and western blotted for PIN1 and $\alpha$-Tubulin. Three mice were treated with DMSO and saline and 5 mice were treated with LPS and saline or LPS and roscovitine for each genotype. The upper set of PIN1 and $\alpha$-Tubulin blots has -/samples except for one $+/+$ sample, placed with them as a positive control. The lower set of blots blot has $+/+$ samples except for one marked -/-. The numbers on the left show the position of molecular weight markers in $\mathrm{kDa}$. The protein detected is indicated on the right.
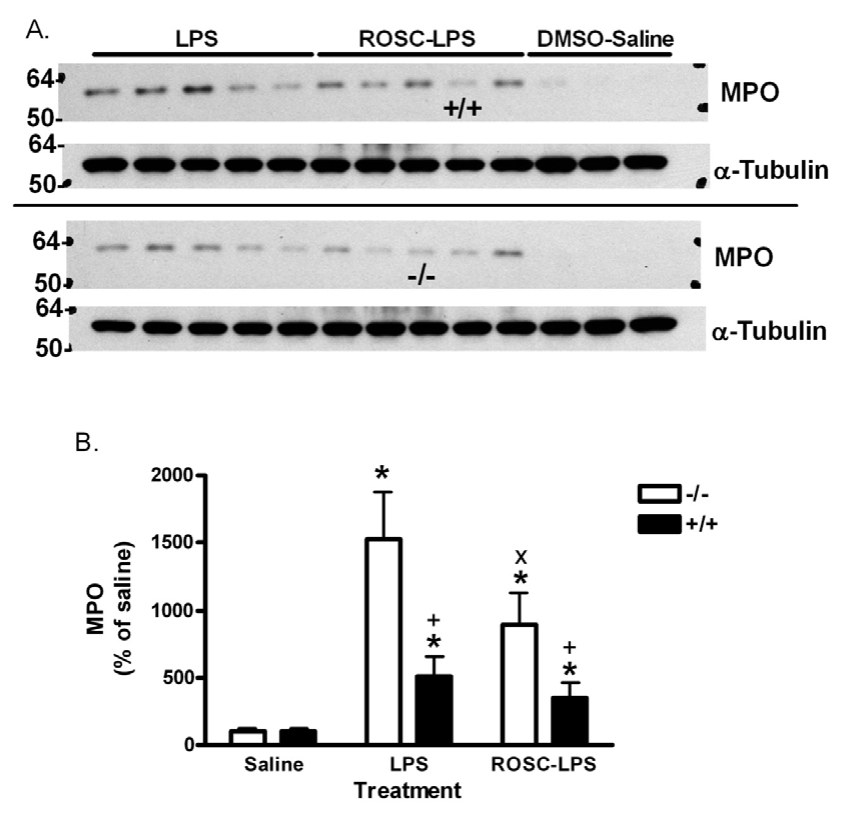

Figure 2. Effect of LPS and Roscovitine on MPO in $+/+$ and -/- mice. A) Lung tissue from mice treated as in figure 1 and western blotted for MPO. Upper blots are -/- samples except for one $+/+$ sample as marked. Lower blots are $+/+$ samples except for one marked $-/-$. Molecular weight markers are indicated on the left. B) Image analysis of blots in A. Three mice were treated with DMSO and saline and 5 mice were treated with LPS and saline or LPS and roscovitine for each genotype. Bars are the mean ratio of $\mathrm{MPO} / \alpha-\mathrm{Tubulin}$ signal as a percent of saline-treated group + SE. ${ }^{*}: \mathrm{p}<0.05$ for comparison with $0 \mathrm{mg} \mathrm{LPS} / \mathrm{kg}$ and $+: p<0.05$ for comparison with $-/-$ mice treated the same way. $x: p<0.05$ for comparison between DMSO- and roscovitine-treated -/- mice that received LPS.

suggested that PIN1 normally limits the sensitivity of lungs to the inflammatory actions of LPS. The presumption is that PIN1 modulates signals generated by LPS and mediators.

PIN1 acts on proteins containing pS/T-P motifs. The effects of deleting or manipulating PIN1 on cell function are complicated by the existence of many proteins with $\mathrm{pS} / \mathrm{T}-\mathrm{P}$ in cells. Furthermore, PIN1 can modulate protein function, interaction with other biomolecules, and susceptibility of proteins to other enzymes [23]. PIN1 appears to facilitate Toll receptor 9 signaling, at least in part by maintaining interleukin 1 receptor associated kinase 1 function, 

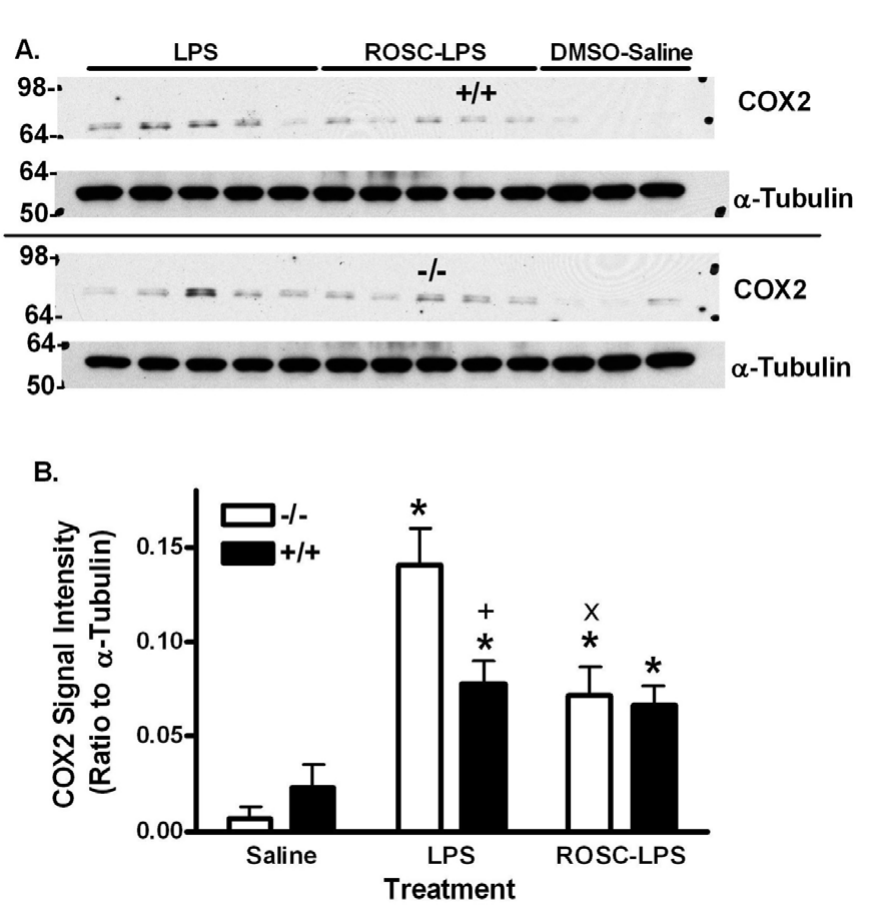

Figure 3. Effect of LPS and Roscovitine on COX2 in +/+ and -/- mice. A) COX2 in lungs from mice treated as in figure 1 and western blotted for COX2. Upper blots are -/- samples except for one $+/+$ sample as marked. Lower blots are $+/+$ samples except for one marked -/-. Molecular weight markers are indicated on the left. Three mice were treated with DMSO and saline and 5 mice were treated with LPS and saline or LPS and roscovitine for each genotype. B) Bars are the mean ratio to $\alpha$-Tubulin + SE. *:p $<0.05$ for comparison with $0 \mathrm{mg} \mathrm{LPS} / \mathrm{kg}$ and $+: \mathrm{p}<0.05$ for comparison with $-/-$ mice treated the same way. $\mathrm{x}: \mathrm{p}<0.05$ for comparison between DMSO- and roscovitine-treated -/- mice that received LPS

which also contributes to LPS signaling via Toll receptor 4 [24]. Toll receptor signaling usually activates nuclear factor kappa B leading to inflammatory gene expression. The same group earlier showed the deletion of PIN1 increased degradation of this transcription factor via the proteasome [6]. While these actions suggest that PIN1 knockout should antagonize inflammatory effects of endotoxin in lung, the present results and our earlier study indicate the opposite [2].

One explanation for the previously unexpected anti-inflammatory effect of PIN1 in lung may be that the enzyme has many substrates that could regulate inflammatory responses [23]. For example, we found that COX2 is degraded by calpain proteases and that depletion of PIN1 facilitates the calpain inhibitory effect of the endogenous protein, calpastatin. The resulting suppression of calpain activity in the absence of PIN1 permits super-induction of COX2 in cultured endothelial cells $[25,26]$. The balance of pro- and anti-inflammatory effects of PIN1 presumably depends the population and phosphorylation state of PIN1 substrates. This may also explain why PIN1 knockout has different effects in different tissues and different strains of mice $[2,6,10,27]$.

Phosphorylation of S/T-P is produced by proline directed kinases, such as mitogen-activated protein kinases and CDKs. Other kinases, like protein kinase $\mathrm{C}$, can phosphorylate $\mathrm{S}$ and $\mathrm{T}$ preceding proline, or $\mathrm{S}$ and $\mathrm{T}$ followed by other amino acids. Given previous suggestions that LPS activates CDK5 and that roscovitine can inhibit LPS action in hippocampus [13], and that roscovitine can antagonize lung inflammation due to ventilator-induced injury and Gram-positive Streptococcus pneumoniae or its cell wall component, lipoteichoic acid $[18,19]$, we determined its effects against LPS from Gram-negative $E$. coli here.

As mentioned above, PIN1 knockout increased the sensitivity of C57Bl/6 mice to LPS-induced lung inflammation [2]. There were increases in lung neutrophils, as indicated by MPO levels (Figure 2). COX2 was also increased (Figure 3). Interestingly, roscovitine limited the increases in -/- mice to levels seen in $+/+$ mice treated with LPS. However, roscovitine did not reduce the moderate levels of MPO and COX2 in $+/+$ mice any further. The inhibitory effect of roscovitine was not simply due to the higher response in -/- mice since a higher dose of LPS further increased neutrophil accumulation in $+/+$ mice which was not antagonized by the drug.

It is possible that the excess inflammation in PIN1 -/- mice is mediated by pathways or events that differ from those in $+/+$ mice, and that these pathways are sensitive to roscovitine. Although the pulmonary activity of roscovitine-sensitive CDKs is unknown, PIN1 may directly affect kinases, including some of these CDKs, as well as phosphatases, that might regulate the balance of phosphorylation and dephosphorylation of specific proteins [28-30]. Thus, deletion of PIN1 could lead to a cellular $\mathrm{pS} / \mathrm{T}-\mathrm{P}$ phosphoproteome that is maintained by CDKs. A lack of PIN1 might also limit phosphatase activity towards proteins that are phosphorylated by roscovitine-sensitive kinases. These proteins may contribute to the elevated inflammatory reaction in -/- mice. An examination of the effect of LPS and PIN1 on activities of specific CDKs in lung may suggest specific new targets for therapeutic development.

There is accumulating evidence that polymorphisms, including some in the PIN1 promoter, and population variability in PIN1 expression and function are associated with cancer, rheumatoid arthritis, Alzheimer's disease, some actions of PIN1 modulating agents, and other conditions [31-33]. The results here suggest that prolinedirected kinase inhibitors might be useful in individuals with low PIN1 function, or in combination with drugs targeting PIN1 or its critical substrates [30].

In conclusion, the present study indicates that roscovitine suppresses LPS-induced inflammatory effects in lungs of mice lacking PIN1. Genetic variation in PIN1 or drugs targeting the enzyme may modulate the Gram-negative sensitivity of different individuals, and the effects of CDK antagonists.

\section{Acknowledgements}

We thank Dr. Anthony R. Means of the Duke University Cancer Institute, Durham, NC, and his laboratory for supplying mice for this investigation.

\section{References}

1. Matthay MA, Zemans RL (2011) The acute respiratory distress syndrome: pathogenesis and treatment. Annu Rev Pathol 6: 147-163. [Crossref]

2. Liu T, Schneider RA, Lee NY, Hoyt DG (2014) Peptidylprolyl cis/trans isomerase, NIMA-interacting 1 (PIN1) regulates pulmonary effects of endotoxin and tumor necrosis factor- $\hat{I} \pm$ in mice. Biochem Biophys Res Commun 452: 468-472. [Crossref]

3. Yaffe MB, Schutkowski M, Shen M, Zhou XZ, Stukenberg PT, et al. (1997) Sequencespecific and phosphorylation-dependent proline isomerization: a potential mitotic regulatory mechanism. Science 278: 1957-60. [Crossref]

4. Lu KP, Zhou XZ (2007) The prolyl isomerase PIN1: a pivotal new twist in phosphorylation signalling and disease. Nat Rev Mol Cell Biol 8: 904-916. [Crossref]

5. Lu KP, Liou YC, Zhou XZ (2002) Pinning down proline-directed phosphorylation signaling. Trends Cell Biol 12: 164-172. [Crossref]

6. Ryo A, Suizu F, Yoshida Y, Perrem K, Liou YC, et al. (2003) Regulation of NF-kappaB 
signaling by Pin1-dependent prolyl isomerization and ubiquitin-mediated proteolysis of p65/RelA. Mol Cell 12: 1413-26. [Crossref]

7. Finn G, Lu KP (2008) Phosphorylation-specific prolyl isomerase Pin1 as a new diagnostic and therapeutic target for cancer. Curr Cancer Drug Targets 8: 223-229. [Crossref]

8. Monje P, Hernández-Losa J, Lyons RJ, Castellone MD, Gutkind JS (2005) Regulation of the transcriptional activity of c-Fos by ERK. A novel role for the prolyl isomerase PIN1. J Biol Chem 280: 35081-35084. [Crossref]

9. Ryo A, Nakamura M, Wulf G, Liou YC, Lu KP (2001) Pin1 regulates turnover and subcellular localization of beta-catenin by inhibiting its interaction with APC. Nat Cell Biol 3: 793-801. [Crossref]

10. Yeh ES, Means AR (2007) PIN1, the cell cycle and cancer. Nat Rev Cancer 7: 381388. [Crossref]

11. Esnault S, Shen ZJ, Whitesel E, Malter JS (2006) The peptidyl-prolyl isomerase Pin 1 regulates granulocyte-macrophage colony-stimulating factor mRNA stability in T lymphocytes. J Immunol 177: 6999-7006. [Crossref]

12. Huang H, Rose JL, Hoyt DG (2004) p38 Mitogen-Activated Protein Kinase Mediates Synergistic Induction of Inducible Nitric-Oxide Synthase by Lipopolysaccharide and Interferon-\{gamma\} through Signal Transducer and Activator of Transcription 1 Ser727 Phosphorylation in Murine Aortic Endothelial Cells. Mol Pharmacol 66: 302 311. [Crossref]

13. Kitazawa M, Oddo S, Yamasaki TR, Green KN, LaFerla FM(2005) Lipopolysaccharideinduced inflammation exacerbates tau pathology by a cyclin-dependent kinase 5-mediated pathway in a transgenic model of Alzheimer's disease. J Neurosci 25: 8843-53. [Crossref]

14. Akira S, Takeda K (2004) Toll-like receptor signalling. Nat Rev Immunol 4: 499-511. [Crossref]

15. Ubersax JA, Ferrell JE Jr (2007) Mechanisms of specificity in protein phosphorylation Nat Rev Mol Cell Biol 8: 530-541. [Crossref]

16. Du J, Wei N, Guan T, Xu H, An J, et al. (2009) Inhibition of CDKS by roscovitine suppressed LPS-induced *NO production through inhibiting NFkappaB activation and BH4 biosynthesis in macrophages. Am J Physiol Cell Physiol 297: C742-9. [Crossref]

17. Jhou RS, Sun KH, Sun GH, Wang HH, Chang CI, et al. (2009) Inhibition of cyclindependent kinases by olomoucine and roscovitine reduces lipopolysaccharideinduced inflammatory responses via down-regulation of nuclear factor kappaB. Cell proliferation 42: 141-149. [Crossref]

18. Hoogendijk AJ, Roelofs JJ, Duitman J, van Lieshout MH, Blok DC, et al. (2012) R-roscovitine reduces lung inflammation induced by lipoteichoic acid and Streptococcus pneumoniae. Mol Med 18: 1086-1095. [Crossref]

19. Hoogendijk AJ, Kuipers MT, van der Poll T, Schultz MJ, Wieland CW (2012) Cyclindependent kinase inhibition reduces lung damage in a mouse model of ventilatorinduced lung injury. Shock 38: 375-380. [Crossref]
20. Atchison FW, Capel B, Means AR (2003) Pin1 regulates the timing of mammalian primordial germ cell proliferation. Development 130: 3579-3586. [Crossref]

21. Bradford MM (1976) A rapid and sensitive method for the quantitation of microgram quantities of protein utilizing the principle of protein-dye binding. Analytical Biochemistry 72: 248-254. [Crossref]

22. Snedecor G and Cochran W (1980) Statistical Methods, Iowa State University Press, Ames, IA.

23. Liou YC, Zhou XZ, Lu KP (2011) Prolyl isomerase Pin1 as a molecular switch to determine the fate of phosphoproteins. Trends Biochem Sci 36: 501-514. [Crossref]

24. Tun-Kyi A, Finn G, Greenwood A, Nowak M, Lee TH, et al. (2011) Essential role for the prolyl isomerase Pin1 in Toll-like receptor signaling and type I interferon-mediated immunity. Nat Immunol 12: 733-741. [Crossref]

25. Liu T, Schneider RA, Shah V, Huang Y, Likhotvorik RI, et al. (2009) Protein Never in Mitosis Gene A Interacting-1 regulates calpain activity and the degradation of cyclooxygenase-2 in endothelial cells. J Inflamm (Lond) 6: 20. [Crossref]

26. Liu T, Schneider RA, Hoyt DG (2011) Calpastatin is regulated by protein never in mitosis gene A interacting-1 (PIN1) in endothelial cells. Biochem Biophys Res Commun 414: 581-586. [Crossref]

27. Yeh ES, Lew BO, Means AR (2006) The loss of PIN1 deregulates cyclin E and sensitizes mouse embryo fibroblasts to genomic instability. J Biol Chem 281: 241-251. [Crossref]

28. Olsten ME, Weber JE, Litchfield DW (2005) CK2 interacting proteins: emerging paradigms for CK2 regulation? Mol Cell Biochem 274: 115-124. [Crossref]

29. Rudrabhatla P, Albers W, Pant HC (2009) Peptidyl-Prolyl Isomerase 1 Regulates Protein Phosphatase 2A-Mediated Topographic Phosphorylation of Neurofilament Proteins. The Journal of Neuroscience 29: 14869-14880. [Crossref]

30. Litchfield DW, Shilton BH, Brandl CJ, Gyenis, L (2015) Pin1: Intimate involvement with the regulatory protein kinase networks in the global phosphorylation landscape. Biochimica et Biophysica Acta (BBA) - General Subjects 1850: 2077-86.

31. Nagaoka A, Takizawa N, Takeuchi R, Inaba Y, Saito I, et al. (2011) Possible involvement of peptidylprolyl isomerase Pin1 in rheumatoid arthritis. Pathol Int 61: 59-66. [Crossref]

32. Ma SL, Tang NL, Tam CW, Lui VW, Lam LC, et al. (2012) A PIN1 polymorphism that prevents its suppression by AP4 associates with delayed onset of Alzheimer's disease. Neurobiol Aging 33: 804-813. [Crossref]

33. Takahashi K, Shimizu T, Kosaka K, Hidaka M, Uchida C, et al. (2014) Role of prolyl isomerase pin1 in pathogenesis of diseases and remedy for the diseases from natura products. Curr Drug Targets 15: 973-981. [Crossref]

Copyright: (C2016 Newell BW. This is an open-access article distributed under the terms of the Creative Commons Attribution License, which permits unrestricted use, distribution, and reproduction in any medium, provided the original author and source are credited. 